\title{
A Review on Substantial Equivalence of Medical Devices-USFDA
}

\author{
Swathilakshmi U*, Revathi K, Sowjanya K, Shailaja P, Sravani S and Indira P \\ Andhra University, College of Pharmaceutical Sciences, India
}

Submission: November 17, 2017; Published: December 15, 2017

*Corresponding author: Swathilakshmi U, Andhra University, College of Pharmaceutical Sciences, India, Email: uswathilakshmi@gmail.com

\begin{abstract}
Any company or manufacturer want to market their product in United States first time, the manufacturer must determine the classification of the device and predicate to their device (innovator device) and submit the substantial equivalence data in the form of premarket notification $(510(\mathrm{k}))$ or premarket approval. After submitting the substantial equivalence report, FDA start the decision making processes it contains the parameters like intended use, classification of device, technological characteristics, and safety and effectiveness data. If device found to be non substantial equivalent to the predicate the marketing authorization will reject by FDA review committee, the device is substantial equivalent to predicate FDA issues approval for market of medical device in United States.
\end{abstract}

Keywords: Substantial equivalence 510(k); Pre market approval; Intended use; Technological characteristics; Predicate device; Risk; USFDA

\section{Introduction}

The Food and Drug Administration's (FDA) 510(k) program is the dominant pathway to market among medical devices. of devices requiring premarket review, about $2 \%$ reach the market via premarket application (PMA) approval. A 510(k) clearance is based upon a finding of "substantial equivalence" (SE) [1]. Substantial equivalence review is much criticized. It is frequently compared unfavorably to PMA approval as a means of establishing the safety and effectiveness of new devices [2]. When a firm wishes to market a medical device for the first time, or has significantly modified a device that is already marketed, the classification of the proposed device must be determined. According to section 513(a) (1) of the FD\&C Act (21 U.S.C. § 360c (a) (1)), the three device classes are defined as follows:

\section{Class I}

Devices are subject to a comprehensive set of regulatory authorities called general controls that are applicable to all classes of devices [3].

\section{Class II}

Devices for which general controls, by themselves, are insufficient to provide reasonable assurance of the safety and effectiveness of the device, and for which there is sufficient information to establish special controls to provide such assurance [4].

\section{Class III}

Devices for which general controls, by themselves, are insufficient and for which there is insufficient information to establish special controls to provide reasonable assurance of the safety and effectiveness of the device. Class III devices typically require premarket approval [5]. By statutory default, the device is in Class III requiring PMA approval, unless FDA issues an order classifying it in Class I or II. To obtain such an order, the firm submits a premarket notification (or " $510(\mathrm{k})$ submission") demonstrating that the proposed device is substantially equivalent to a legally marketed Class I or II device or to a "Preamendment" device marketed as of May 28, 1976 [6]. The comparison device is customarily called a predicate device (Table 1).

If FDA finds "substantial equivalence" (SE), then the proposed device is placed in the same class as the predicate device (e.g., Class I or II) and subjected to the same general and/ or special controls to provide reasonable assurance of safety and effectiveness. If FDA finds the two devices are "not substantially equivalent" (NSE), then the proposed device remains in Class III 
and must receive PMA approval. There is a potential exception to this automatic Class III designation if the device is novel, but does not pose a level of risk that justifies Class III designation. In such cases, FDA has authority to develop a new (de novo) classification regulation classifying the device as Class I or II and specifying the controls needed to reasonably assure safety and effectiveness [7].

Table 1: Comparison of predicate device- an example.

\begin{tabular}{|c|c|c|c|}
\hline Characteristics & MSO Hip Joint (510[k]\# TBD) & $\begin{array}{l}\text { Predicate Hip Joint (510[k]\# e.g., } \\
\text { K13XXXX*) }\end{array}$ & Comments \\
\hline Intended Use & $\begin{array}{l}\text { Intended for use in total hip replacement for } \\
\text { reduction of pain and improved hip function in } \\
\text { skeletally mature patients }\end{array}$ & $\begin{array}{l}\text { Intended for use in total hip replacement for } \\
\text { reduction of pain and improved hip function } \\
\text { in skeletally mature patients }\end{array}$ & $\mathrm{N} / \mathrm{A}$ \\
\hline Indications for Use & $\begin{array}{l}\text { Non-inflammatory degenerative joint disease } \\
\text { such as painful hip dysplasia } \\
\text { Inflammatory degenerative joint disease such as } \\
\text { rheumatoid arthritis } \\
\text { Correction of functional deformity } \\
\text { Revision procedures where other treatments or } \\
\text { devices have failed }\end{array}$ & $\begin{array}{c}\text { Non-inflammatory } \\
\text { degenerative joint disease such as painful hip } \\
\text { dysplasia } \\
\text { Inflammatory degenerative joint disease such } \\
\text { as rheumatoid arthritis } \\
\text { Correction of functional deformity } \\
\text { Revision procedures where other treatments } \\
\text { or devices have failed }\end{array}$ & $\mathrm{N} / \mathrm{A}$ \\
\hline Sterility & Gamma irradiation & Gamma irradiation & $\mathrm{N} / \mathrm{A}$ \\
\hline Design & $22 \mathrm{~mm}$ & $28 \mathrm{~mm}, 32 \mathrm{~mm}, 36 \mathrm{~mm}$ & $\begin{array}{l}\text { Added smallest head } \\
\text { into the family }\end{array}$ \\
\hline Materials & Biolox Forte manufactured by Ceram Tec & Biolox Forte manufactured by CeramTec & $\mathrm{N} / \mathrm{A}$ \\
\hline
\end{tabular}

Requirements for Substantial Equivalence of Medical Devices

Medical devices marketed in the United States are subject to the regulatory controls in the Federal Food, Drug, and Cosmetic Act (FD\&C Act) and the regulations in 21 CFR Parts 1-58, 8001299. Medical devices that emit radiation are also subject to regulations for radiation-emitting electronic products cited in 21CFR Parts 1000-1050. Some requirements apply to medical devices before they are marketed (premarket requirements), and other apply to medical devices after they are marketed (post market requirements).

\section{Premarket Requirements}

Manufacturer must follow the steps below prior to marketing a medical device in the United States

\section{Step-1: Classify your device}

The first step in preparing a device for marketing is to find the federal regulation that classifies your device. A medical device is defined by law in the section 201(h) of the FD\&C Act, and the classification, which may be found in the Code of Federal Regulations, determines the regulatory path and regulatory requirements for your device.

a) ClassI-Lowest Risk (subject to general controls)

Example: manual toothbrush.

b) Class II-Moderate Risk (subject to general controls and special controls)
Examples: male condoms and non-invasive blood pressure monitors.

c) Class III- Highest Risk (subject to general controls and premarket approval)

Example: heart valve.

\section{Step-2: Select the correct premarket submission}

After the device classification, you then select the premarket submission required for that regulation. The most common types of premarket submissions include.

510(k) (Premarket notification): Some Class I and most Class II devices require a $510(\mathrm{k})$. In a $510(\mathrm{k})$, the sponsor must demonstrate that the new device is "substantially equivalent" to a predicate device in terms of intended use, technological characteristics, and performance testing, as needed.

PMA (Premarket approval): Most Class III devices require a PMA. A PMA is the most stringent type of premarket submission. Before the FDA approves a PMA, the sponsor must provide valid scientific evidence demonstrating reasonable assurance of safety and effectiveness for the device's intended use.

De Novo (Evaluation of Automatic Class III Designation) De Novo provides a means for a new device, without a valid predicate, to be classified into Class I or II if it meets certain criteria.

HDE (Humanitarian Device Exemption): HDE provides a regulatory path for Class III devices that are intended to benefit patients with rare diseases or conditions. In order for a device 
to be eligible for an HDE, a sponsor must obtain designation as a Humanitarian Use Device (HUD), which is granted through application to FDA's Office of Orphan Products Development (OOPD).

\section{Step-3: Prepare the appropriate information for the premarket submission}

Once you have selected the correct premarket submission type, you must prepare the appropriate information that will be needed.

Information to consider when preparing your premarket submission

Design controls: All Class II and Class III devices must be designed in accordance with Design Controls under the Quality System Regulation (21 CFR 820.30).

Nonclinical testing: The types of information and testing required to market your device are determined by the device classification, mechanisms of operation, technological characteristics, and labeling. Nonclinical testing performed in support of a premarket submission for a medical device must comply with the Good Laboratory Practices (GLPs) in 21 CFR 58.

Clinical evidence: PMAs, HDEs and some 510(k)s and De Novos require clinical evidence. Prior to initiating a clinical study, the study sponsor may need to obtain approval of an Investigational Device Exemption (IDE) by the FDA. The study will also need to be approved by the appropriate Institutional Review Board (IRB). Clinical studies must comply with all applicable IDE regulations and Good Clinical Practices (GCPs).

Labeling: The labeling for a device must be written according to labeling regulations and included in your premarket submission.

\section{Step-4: Send your premarket submission to the FDA and interact with FDA staff during review}

Once you have assembled the appropriate information necessary for your Premarket Submission, you send your Table 2: Elements for submission of $510(k)$ to USFDA-check list.

\begin{tabular}{|c|c|c|c|c|}
\hline Title & Related Information & Yes & No & N/A \\
\hline MDUFMA Cover Sheet & Medical Device User Fee Cover Sheet Premarket Notification [510(k)] Review Fees & & & \\
\hline $510(\mathrm{k})$ Cover Letter & CDRH Premarket Review Submission Cover Sheet (Form 3514) & & & \\
\hline Indications for Use Statement & Device Advice "Content of a $510(\mathrm{k})$ " & & & \\
\hline $510(\mathrm{k})$ Summary or $510(\mathrm{k})$ Statement & $\begin{array}{l}\text { Device Advice “Content of a } 510(\mathrm{k}) \text { " } 510(\mathrm{k}) \text { RTA Policy for } 510(\mathrm{~K}) \text { Guidance } \\
\text { Summary Checklist Truthful }\end{array}$ & & & \\
\hline Truthful and Accuracy Statement & Device Advice “Content of a 510(k)" & & & \\
\hline Class III Summary and Certification & Class III Summary and Certification Form & & & \\
\hline $\begin{array}{l}\text { Financial Certification or Disclosure } \\
\text { Statement }\end{array}$ & $\begin{array}{l}\text { FORM FDA 3454, Certification: Financial Interests and Arrangements of Clinical } \\
\text { Investigators FORM FDA 3455, Disclosure: Financial Interests and Arrangements } \\
\text { of Clinical Investigators Financial Disclosure by Clinical Investigators }\end{array}$ & & & \\
\hline
\end{tabular}

submission to the FDA and interact with FDA staff during review. There is a user fee associated with the submission of a $510(\mathrm{k})$ or a PMA.

eCopy: Premarket submissions must include an electronic copy (eCopy) on a compact disc (CD), digital video disc (DVD), or a flash drive.

Administrative filing review: After a premarket submission is received, the FDA conducts an administrative review to assess whether the submission is sufficiently complete to be accepted for substantive review.

Interactive review: While a submission is under review, FDA staff communicates with applicants to increase the efficiency of the review process.

\section{Step-5: Complete establishment registration and device listing}

A device facility must register its establishment and list its devices with the FDA. If a device requires premarket clearance or premarket approval prior to marketing (i.e., the medical device is not exempt), the device firm must wait until it receives FDA clearance or approval before registering and listing. Registration of a device establishment, assignment of a registration number, or listing of a medical device does not in any way denote clearance or approval of the establishment or its products by the FDA [8].

Elements for the submission of $510(k)$ premarket notification to the USFDA: $510(\mathrm{k})$ review is both the mechanism by which a manufacturer seeks marketing authorization for a new device and by which FDA classifies devices into their appropriate regulatory category. Because devices are classified according to the level of regulatory control necessary to provide a reasonable assurance of safety and effectiveness, classification of a new device through the $510(\mathrm{k})$ process requires FDA to determine the issues of safety and effectiveness presented by the new device, and the regulatory controls necessary to address those issues. To submit the $510(\mathrm{k})$ manufacturers should at least include the following data as follows [9] (Table 2). 


\section{Modern Applications of Bioequivalence \& Bioavailability}

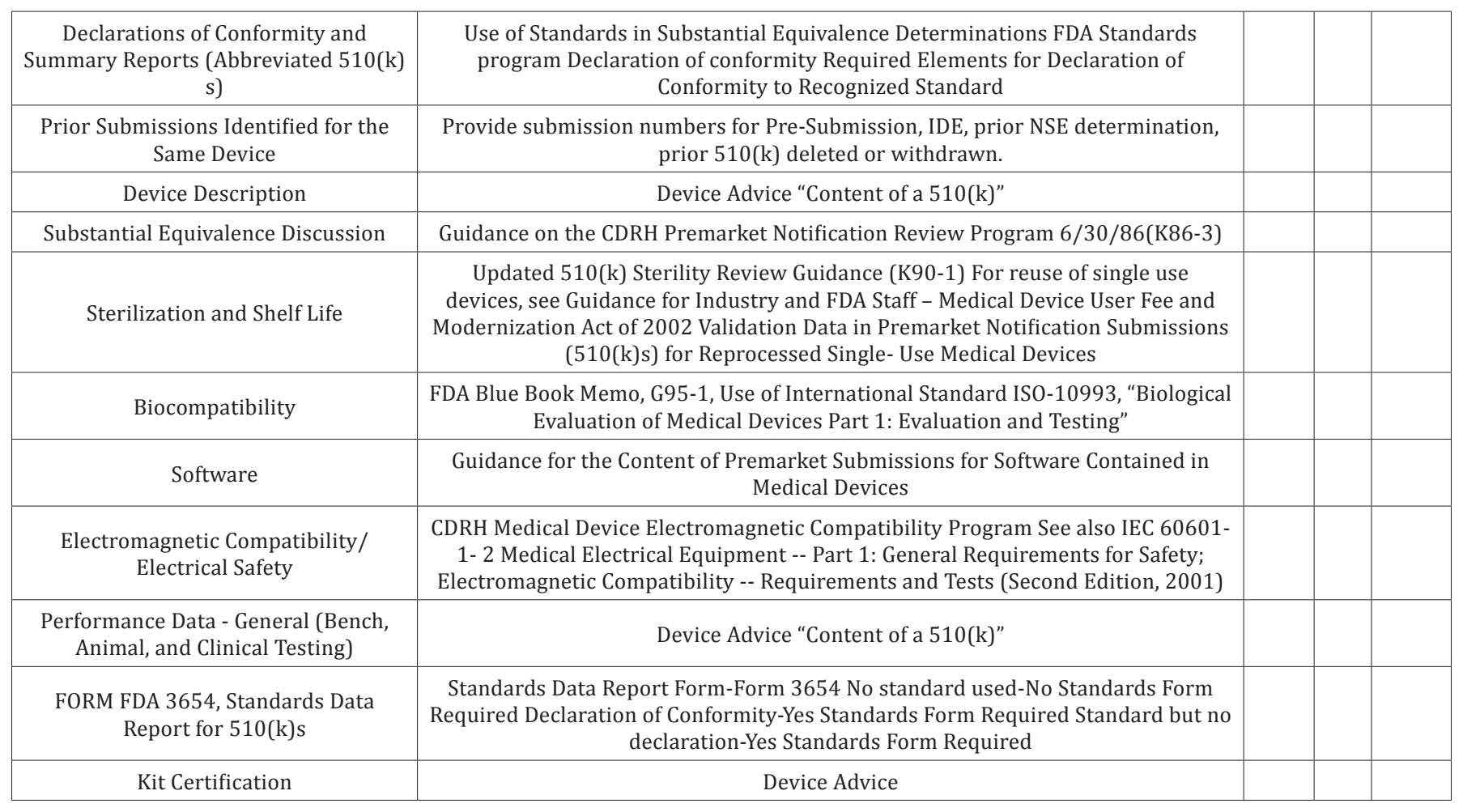

Decision making process for $\mathbf{5 1 0 ( k )}$ submission:

The substantial equivalence determination is the heart of the $510(\mathrm{k})$ program. Under the statutory definition of this term, 9 the proposed and predicate devices must have the same intended use. They may, however, vary in their technological characteristics, if the proposed device is shown to be equally safe and effective and does not present different questions of safety and effectiveness. Supporting data to show equivalent safety and effectiveness may include bench, animal, and/or clinical testing. To understand substantial equivalence review, one should review the decision making flow chart FDA uses to implement the statute. There are potentially six decisions FDA needs to make:

Decision 1: The first question FDA must answer is whether the $510(\mathrm{k})$ submission identifies at least one legally marketed device as the "predicate device".

Decision 2: FDA's determination of intended use of a device is based on the proposed labeling submitted in a $510(\mathrm{k})$. When a review of the indications for use and all other information in the proposed labeling submitted with a $510(\mathrm{k})$ supports an intended use that is the same as that of the predicate device.

Decision 3: A $510(\mathrm{k})$ submission must identify the various features of the proposed and predicate devices, including design, materials, energy source, hardware/software, reagents, and so forth. Obviously, if the proposed and predicate devices are the same, then they will be found substantially equivalent.

Decision 4: If the proposed device raises different questions regarding technological characteristics, then it will be found NSE.
Decision 5a: If the questions of safety and effectiveness are the same between the proposed and predicate devices.

Decision 5b: At this last step, FDA may decline to find substantial equivalence if it concludes that the resulting safety and effectiveness data presented are insufficient to show that the proposed device is at least as safe and effective as the predicate device [10-12] (Figure 1).

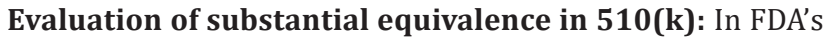
guidance document, The 510(k) Program: Evaluating Substantial Equivalence in Premarket Notifications (510k) describes some critical steps in the SE process:

a. The appropriate use of multiple predicate devices

b. Determining whether a new device has a new intended use

c. Determining whether the different technological characteristics of your device mean you can or cannot use the predicate device

d. When FDA will require performance data

e. How to develop 510(k) summaries

The federal law requires FDA to consider the least burdensome means of demonstrating substantial equivalence, when requesting information from the $510(\mathrm{k})$ submitter. FDA gives a lot of detail about use of predicates -- including multiple predicate devices and "reference" predicates [13]. 


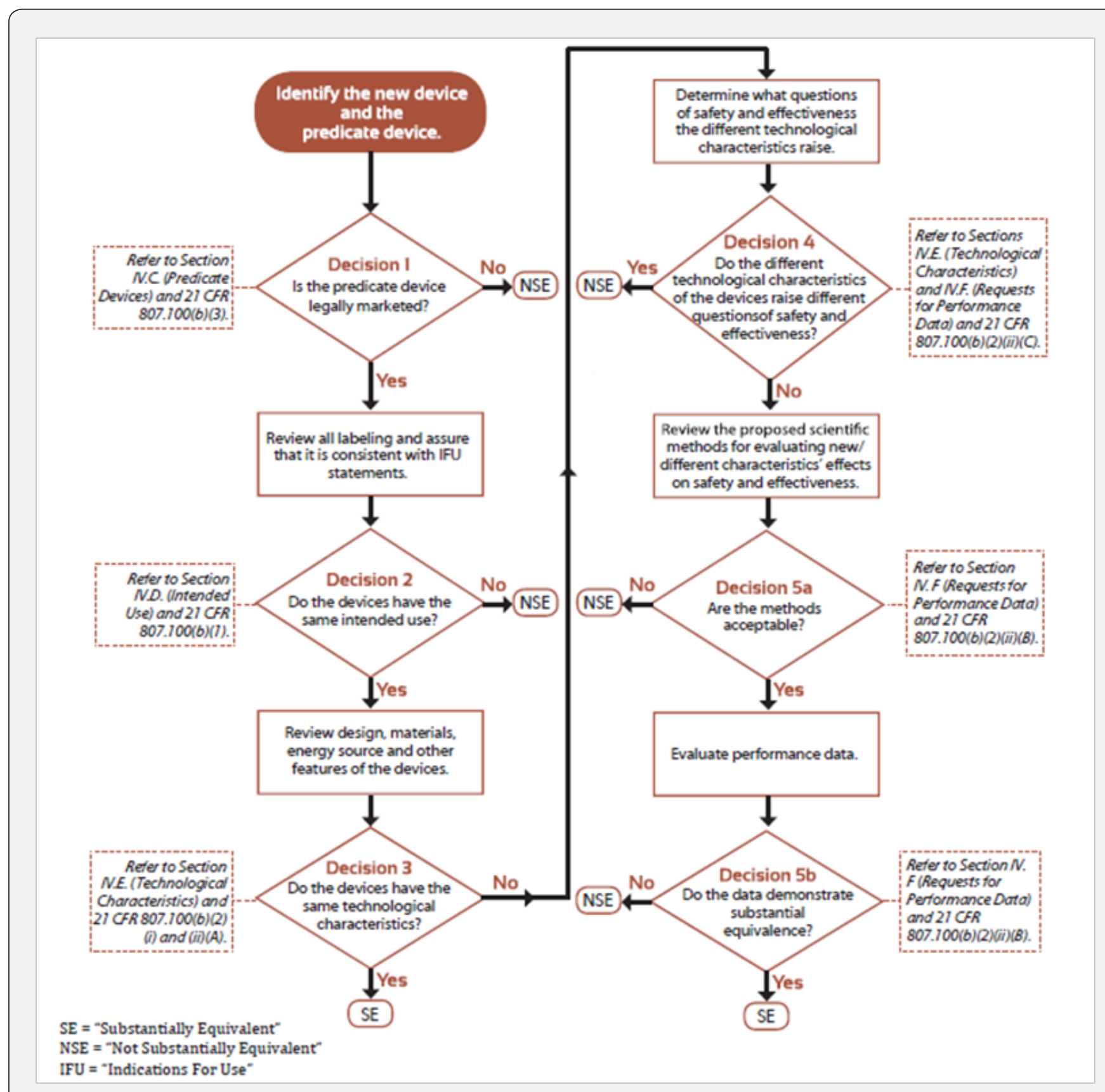

Figure 1:

\section{Conclusion}

The review on substantial equivalence of medical devices in United States gives the knowledge on regulatory requirements for the submission of premarket notification $510(\mathrm{k})$ to the FDA and FDA decision making processes for obtaining market authorization to the manufacturer.

\section{Acknowledgment}

We express our sincere gratitude to $\mathrm{Dr} S$ Prashanth, Blessy.A.Daniel from S3V Vascular Technologies Pvt. Ltd., Bangalore for their immense support and Prof. J.Vijaya Ratna,
Dr.P.Shailaja, University College of Pharmaceutical Sciences, Andhra University for giving support to write review on substantial equivalence of medical devices.

\section{References}

1. Institute of Medicine (IOM), Medical Devices and the Public's Health: The FDA $510(\mathrm{k})$ Clearance Process at 35 Years, at 4 (2011) [hereinafter "IOM Report"]. In fiscal year 2013, FDA issued 2,895 clearances and 44 PMA approvals. FDA, Agenda for Quarterly Meeting on MDUFA III (FY 2013-2017) Performance, at 6, 157 (Apr. 29, 2014). These numbers are typical of the annual gap between $510(\mathrm{k})$ clearances and PMA approvals). 
2. Goldberger B (2007) The evolution of substantial equivalence in FDA's premarket review of medical devices, 56 food \& drug l j In: Buren MV (Ed.) Closing the loopholes in the regulation of medical devices: the need for congress to reevaluate medical device regulation, 17 Health Matrix 441, 17(2).

3. http://www.fda.gov/MedicalDevices/DeviceRegulationandGuidance/ GuidanceDocuments/ucm285317.htm.

4. http://www.fda.gov/downloads/MedicalDevices/DeviceRegulationandGuidance/Guidance Documents/ UCM311176.pdf

5. http://www.fda.gov/medicaldevices/

6. WWW.Device Advice Premarket Notification [510(k)]. (2013) Ivy Sports Medicine v. Sebelius, No. 11-1006, slip op. at 27-33.

7. https://www.fda.gov/medicaldevices/deviceregulationandguidance/ howtomarketyourdevice/
8. Bauman J (2012) The 'Déjà vu effect evaluation of united states medical device legislation, regulation, and the food and drug administration's contentious 510(k) program. Food Drug Law J 67(3): 337-361.

9. VanBuren M (2007) Closing the Loopholes in the regulation of medical devices: The need for congress to reevaluate medical device regulation. Health Matrix: The Journal of Law-Medicine 17(2): 441-465.

10. An elaborate procedural regulation for this rarely used procedure was issued in 1996 (21 C.F.R. Part 810).

11. C.F.R. § 801.421 (1990); id. § 809.30 (1997).

12. https://michaelhcohen.com/2016/07/fda-medical-device-guidancesubstantial-equivalence/

\section{Your next submission with Juniper Publishers will reach you the below assets}

- Quality Editorial service

- Swift Peer Review

- Reprints availability

- E-prints Service

- Manuscript Podcast for convenient understanding

- Global attainment for your research

- Manuscript accessibility in different formats

( Pdf, E-pub, Full Text, Audio)

- Unceasing customer service

Track the below URL for one-step submission https://juniperpublishers.com/online-submission.php 